\title{
The Role of Research in the Training of Residents
}

\author{
Hans-J. Reulen \\ Department of Neurosurgery, Ludwig Maximilians University Munich, Germany
}

\section{Key Words}

Research rotation - Categories of research - Selection of a research project

\section{Introduction}

Konrad Messmer and the author were the first two residents of Walter Brendel when he moved from Nauheim to the Chirurgische Klinik 'Nußbaumstrasse' in Munich, and experienced the change to the newly founded Institute of Surgical Research in the sheltered Department of Surgery. They succumbed - as later many others too - to the 'horse whisperer', the phenomenon Walter Brendel, who understood like only few teachers to rouse in the young medical doctors and students enthusiasm and craving for knowledge. After the long and partially very dry studies of medicine, he offered the possibility to become creative and take over personal responsibility in a group, a novelty at those times which had still a very hierarchical structure. Later Konrad Messmer continued this unique institute in Munich with the same high quality and in his proper 'Badisch-Alemannisch' mentality: straight forward and success oriented, preparing for many young colleagues the basis for an academic career, but always cherishing the same spirit of openness, tolerance and recognition of achievements, notwithstanding where they came from.

For the author, those scientific activities and the learned capability to logically analyse problems, to ratio- nalise and draw the required conclusions have become an essential part of his later clinical activities as a neurosurgeon and academic teacher. The author has always tried to mediate these aspects to his younger colleagues. Naturally, he also experienced as a young clinical resident how frustrating and demoralizing a surgical training could be when no climate of systematic support and stepwise escalation of responsibility and surgical skills existed. This was one of the reasons why he, as responsible academic teacher, inaugurated a structured training in his department [1]. The scope of such a resident training for becoming a competent surgeon and clinician always included the possibility for a research rotation of 1-2 years. At present many discussions are going on concerning the value of scientific training besides the time-consuming clinical training. The author, after many years of experience, is of the opinion that a scientific activity is not only required for formal reasons to gain a title, it is of genuine and paramount importance for an academic career. These aspects will be discussed in the following chapters.

\section{The Goals of a Research Rotation}

What do we expect and what are the goals of such a research rotation? Most of the academic programme directors or chairmen consider a research period an essential component of education, although most agree that not every resident needs such a rotation [2-9]. If we look at the background of our successful neurosurgical teachers, most of them had such an elective exposure to research.

\begin{tabular}{ll}
\hline KARGER & (c) 2002 S. Karger AG, Basel \\
Fax +4161306 1234 & 0014-312X/02/0342-0013\$18.50/0 \\
$\begin{array}{l}\text { E-Mail karger@karger.ch } \\
\text { www.karger.com }\end{array}$ & $\begin{array}{l}\text { Accessible online at: } \\
\text { www.karger.com/journals/esr }\end{array}$
\end{tabular}

\footnotetext{
Prof. Dr. Hans-J. Reulen

Department of Neurosurgery, Ludwig Maximilians University

Schwojerstrasse 19, D-81249 München (Germany)

Tel. +49 89864 2524, Fax +498986307852

E-Mail Ilona.Anders@nc.med.uni-muenchen.de
} 
Table 1. Categories of Research in Neurosurgery

A Fundamental Basic Neurosciences (blue sky research)

B Laboratory studies simulating clinical diseases (experimental cerebral vasospasm, brain edema, experimental brain tumors, etc.)

C Applied clinical research (application of basic research techniques to a clinical problem)

D Research related to technical innovations and to improve surgical techniques

(neuronavigation, functional mapping, laser-technique, instrumentation and biomechanics)

E Clinical observational studies

(retrospective studies, case reports, prospective non-randomized studies, studies on natural course or outcome)

F Randomized prospective controlled trials

The goal of a well organised research rotation is to gain an understanding of the intellectual processes involved in collecting, analysing and interpreting clinical observations in a systematic way [10-13]. Such experience will significantly improve the individual's rational approach to the management of patients, the critical judgement of his own work and the literature [5].

George Ojeman in 1985 [5, 14] wrote about the role of research training in a neurosurgical residency: 'The essential features of research are making systematic observations and organizing these into hypothesis and written documents. Often, but not always, this is done in a planned experiment. With this general definition, research training has a place in every neurosurgical residency program regardless of the trainee's ultimate career goals and even if they do not continue with research, for opportunities to make new observations - of unique cases, the effects of therapy, pathophysiology of neurosurgical diseases, or the function of the nervous system - will occur in every neurosurgical career.'

Some more goals could be added which may represent a second level. The resident should be introduced to the art of science in a way that he learns and experiences the real excitement of uncovering and describing new knowledge. Also he should come to a point where he is able to start his own research project, raise funds, and teach students and younger colleagues.

It is a matter of fact that in our training institutions there are residents who are planning an academic career, and others who plan to follow a clinical career, although it must be stressed that many trainees at that stage of their career are unsure of their interests. With the above definitions a wide range of options can be offered to both groups, according to their specific interests.

\section{Selection of a Research Area}

Different structures are used to organise research rotations. Some departments focus exclusively on research training in a laboratory within the department under the guidance of neurosurgical faculty members experienced in research. Others prefer to send their trainees to a different institution where applied clinical research is sought, particularly if the own department does not have appropriate conditions, and finally a third group of departments prefers rotation in an area of basic research in one of the basic neuroscience institutions. Thus, as shown in table 1, a wide range of possibilities is offered, extending from fundamental basic research in neurosciences to patient oriented studies and finally to randomized controlled trials.

The important question is whether all these options do have the same rating in the context of neurosurgical training. Can we achieve the above defined goals of research rotation both with a rotation in basic research - for instance tissue slices - and participating in a prospective clinical trial?

There are certainly arguments that strongly support clinically oriented research. This is advocated by most of the experienced programme directors. A successful academic career depends on two pillars, (a) to perform competent clinical patient care and (b) to generate high-level research [8]. Thus, clinical practice and research projects regularly compete for the academic neurosurgeon's time. This is a challenging conflict that can hardly be solved by the individual neurosurgeon, particularly if other tasks like administration, teaching, etc. have also to be performed. In contrast to colleagues in neurology or internal medicine, surgeons spend a large part of their day in the operation theatre. The time remaining for research projects is always limited. Therefore when choosing a research area, there are definite advantages to combine research with the individual's field of clinical interest, for instance working on vasospasm if the main clinical interest is vascular neurosurgery. Thus the neurosurgeon may use questions posed on a ward round as subject for an adequate study, be it experimental or clinical. Such studies are likely to influence the neurosurgeon's future practice.

During the past 25 years a deep change in the understanding and execution of neurosurgery has occurred. In 
the 60 s and 70s, it was still possible for one person to have an overview of more or less all technical procedures as well as the theoretical knowledge. Studies on the regional blood flow ( $\mathrm{rCBF}$ ) in the vicinity of a brain tumor, on the course of intracranial pressure following severe head injury, etc. improved the overall comprehension of the pathophysiologic processes or nature of the disease and could be understood by every neurosurgeon. Most of the scientific publications at that time were understandable and of interest for the majority of neurosurgeons.

In the last 10 to 15 years many neurosurgeons tried to concentrate increasingly on specific areas as for instance neurooncology, functional and stereotactic, spinal neurosurgery, skull base surgery, posterior fossa surgery, pediatric neurosurgery, etc. and consequently in all those fields a more profound knowledge was built up involving new technical operative skills and procedures, improvement of the technical tools, etc. This finally led to the development of subspeciality areas as we have them today in many departments, a development which offers to patients a higher competence in a specific section and which cannot be reversed any more. In any of those subspecialities the literature has increased considerably so that today it has become impossible to view the complete new information. Furthermore a growing inclination can be observed to plan and organize research projects in a way that the criteria for class I evidence is met [8, 13].

This change in paradigm coincided with a change in fields of research. There are now much more research areas than in the sixties or seventies. Each one of the subspeciality areas comprises many possibilities, again ranging from basic research to randomized controlled clinical trials, as shown in table 1.

As a consequence and taking into account the obvious tendency of our young colleagues to focus their clinical work on one of the various subspeciality areas of neurosurgery, the choice of the research topic will become even more important. Two examples are given below:

A resident in his/her third or fourth year of training received a fairly good overview of most clinical areas. He/ she decides that his/her major interest is spinal neurosurgery, and, after finishing his/her regular training programme, wishes to acquire special knowledge in this field by entering a respective fellowship in spinal neurosurgery. It would be logical to choose for his/her research rotation a project closely related to his/her future work, in this case for instance spinal neuronavigation, spinal surgical anatomy, spinal biomechanics, instrumentation, etc.

It would not be logical or even a waste of time, however, if he/she got involved for example in studies on hip- pocampus slices, experimental studies on vasospasm, or any other project far away from his/her clinical interest. Even with the best introduction into the art of science, the final result of such studies would not likely substantially influence his/her practice in spinal neurosurgery. It is most probable that at the end of such a research rotation, he/she would drop these studies. Such a wrong selection of research is one of the reasons why many young neurosurgeons after years of research and successful publications do not pursue their activities after having received their PhD, habilitation or title of professor. Cases are well known where over a certain period of time a scientific activity was performed only in order to gain an academic title. This is obviously a waste, as they would rather be qualified to instruct younger trainees, taking into account the time some individuals invest in research.

Another trainee at the end of his/her second or third year of training sees his/her future commitment in neurooncology and plans to add a neurooncological fellowship after having finished the regular residency programme. After several talks with the programme director he/she uses his/her elective time to work 6 months in an oncology department to learn the theoretical and practical principles of chemotherapy and then participate as the local investigator in a multicenter prospective randomised study on brain tumor therapy. There is no doubt that with an appropriate supervision and support, this trainee will learn much from such an experience. With this knowledge he/she will be able to later extend his/her studies and organize projects by him/herself. The author is convinced that it is one of the important goals of training that at a certain point our trainees become independent and able to organise their own research projects. Such candidates will form the future cadres in academic neurosurgery and also represent the necessary links to the other neuroscience communities [13].

\section{When Should Research Start in the Planning of the Neurosurgical Training Programme?}

Should it be done at the beginning or even before starting clinical practice, should it be done after a certain time of clinical exposure or should it rather be towards the end of the programme?

Probably there is no definite and generally valid answer to this question since one will find individual success stories for all three situations. However, there are convincing arguments that a research rotation should be recommended for the majority of our trainees after at least 
one, but not later than two or three years of clinical practice in neurosurgery [14]. It appears that in Japan research rotation is organized in a similar way [3].

It seems wise to first observe the clinical abilities and conduct of a young candidate, and then only, in cooperation with him, choose a suitable scientific activity. Certainly there are exceptions, for instance, someone who already has a $\mathrm{PhD}$, and for some reasons decides to become a neurosurgeon.

The other extreme would be to organize the research period at the end of the residency programme. At that stage, an intelligent resident would know his/her clinical interests and also have the desire to acquire the tools for a more systematic and scientific approach to some unsolved problems. However, this is exactly the time when his/her surgical progress and success are greatest and his/ her interests are focused entirely on improving his/her surgical skills and techniques, acquiring new surgical methods, etc. There will certainly be a collision of interests; often this conflict is solved by economic aspects, and some very gifted young colleagues may be lost.

If the resident starts with a period of clinical neurosurgery, there are obvious advantages for both teacher and trainee. The arguments for the teacher are: The resident can be observed in his clinical and social performance, his problem-solving skills, his ability to perform under stress, his manual dexterity, his judgement, etc. The teacher can obtain an idea of his talents through observation and regular evaluation by the staff members. He can discuss with him his abilities and interests and find the best solution for this individual. It should be attempted to define a research area that motivates the trainee for a long time and thus will lead to success! The candidate has time to look for a suitable research position in his own or another department, or another institution. The chosen position should serve the interests of both, those of the resident and those of the department, if one considers eventually a continuing activity in a research project. Hence the selection of the topic and of the laboratory is a very important task! It is of no benefit to have the resident participating only as a technician in an ongoing project, he/she should be provided with the skill for independent research and time to prepare funding of a research rotation, if necessary.

Vice versa, during this initial clinical period, the resident has the chance to examine himself whether his decision for neurosurgery as a career was the right one. He will find out how genuine his commitment to patient management really is and pursue training with more passionate intensity. He learns to deal with the unusual, complex case where he sees that routine alone is not sufficient and search of literature and reading become necessary. He has the opportunity to observe the work of various specialists and to develop a specific interest, for instance in vascular or spinal problems, etc. With this background he can plan his research rotation more specifically. He may have an opportunity to participate in a research project.

An important requirement in such a system is that each trainee is assigned to one staff member who takes the role of a tutor and has the responsibility to discuss the trainee's programme at regular intervals (or problems to fulfill the requirements) and to advise him in the above described decision process.

\section{The Role of the Programme Director}

From the previous discussion it results that the chairman, the programme director or an assigned staff member has high responsibility in preparing a research rotation. It is important that with the trainee at regular intervals his abilities and interests are discussed. As soon as the trainee has developed a specific preference for one of the various subspeciality areas, a suitable research topic should be defined. Selection of the research project should be tailored to the individual trainee's clinical interests. The next step would be to choose a well suited laboratory or another department to serve best the needs of the resident for his research rotation. The staff member in such a system certainly plays an important role in the career planning of the resident $[2,4,14]$. Such a procedure will enhance the success of a research rotation and the chances that the trainee will later continue research as part of his career, and the rotational proceeding will no doubt prefer clinically oriented research and reduce purely basic research, as defined previously.

\section{Conclusions}

Research rotation is an important component in the education of a neurosurgical trainee.

Selection of the research area should be tailored to the individual trainee's clinical interest.

Avoid studies far away from the individual trainee's clinical interest.

Select a proper laboratory, institution or clinical research programme for the research rotation.

If possible use the advantages of cooperation with other institutions. 


\section{References}

1 Reulen HJ, Olteanu-Nerbe V, Steiger HJ: The neurosurgical clinic at the Ludwig-Maximilians-University in Munich. Neurosurgery 1996;39:1224-1231.

2 Fahlbusch R: From the scientific idea to its realisation. Principles and Strategies in Neurosurgery. Acta Neurochir 1997;suppl 69:120 125.

3 Hoff JT: Toward better balance. The 1994 presidential address. J Neurosurg 1994;81: 651-655.

4 Langfitt Th W: Research and training in the neurosurgical sciences. J Neurosurg 1982;57: 733-738.

5 Ojeman GA: The role of research rotation in a neurosurgical residency. Neurosurgery 1985 ; 17:138-139.
6 Pickard JD: What is neurosurgical research? Acta Neurochir 1995;133:236-238.

7 Reulen HJ: When should residents be exposed to research? Acta Neurochir 1997;suppl 69: 106-110.

8 Teasdale GM: Research in neurosurgical training. Clinical reviews and trials. Acta Neurochir 1997;suppl 69:116-119.

9 Yoshimoto T, Tominaga T: Contents and structure of a training programme. The Japanese proposal. Acta Neurochir 1997;suppl 69: 81-83.
10 Baethmann A, Meßmer K: Experimentelle Chirurgie; in Schweiberer L, Izbicki IR (eds): Akademische Chirurgie. Berlin, Springer, 1992, pp 177-181.

11 Baethmann A, Messmer K: Stellung der klinischen Forschung in der Chirurgie: Konzept der Experimentellen Chirurgie. Chirurg BDC 1992;31(suppl 1):29-33.

12 Messmer K: Perspektiven der Experimentellen Chirurgie. Chirurg 1990;61:248-250.

13 Messmer K, Baethmann A: Role of surgical research in the training of neurosurgeons. Acta Neurochir 1997;suppl 69:111-115.

14 Ojeman RG: Training the neurosurgeon for the twenty-first century. Surg Neurol 1992;37: 167-174. 